SLE with or without Anti-U1 RNP positivity. Patients satisfying criteria for MCTD were recruited as disease controls. Individual NFC parameters were analysed by a blinded assessor. Changes in three groups were compared using non-parametric tests. Ordinal logistic or linear regression were used wherever applicable to assess any independent association of NFC changes with disease groups.

Results: Total of 81 patients were studied, of which 28 had SLE with RNP+ (age $30.0 \pm 10.37 ; 26$ females), 26 had SLE without RNP positivity (age 29.42 $\pm 9.20 ; 25$ females) and 26 had MCTD (age37.0 $\pm 9.86 ; 25$ females). Capillary density was significantly reduced in MCTD as compared to RNP+SLE patients (5.11 11.69 / $\mathrm{mm}$ vs $7.25 \pm 1.38 / \mathrm{mm}, \mathrm{p}=0.0001)$, as well as in RNP+SLE as compared to RNP negative SLE patients $(7.25 \pm 1.38 / \mathrm{mm}$ vs $8.92 \pm 1.13 / \mathrm{mm}, \mathrm{p}=0.0001)$. Conversely, patients with RNP+SLE had more frequent giant capillaries, enlarged capillaries and ramified/branched capillaries as compared to RNP negative SLE patients $(p=0.047,0.001$ and 0.029 respectively). However, there was no statistical difference in number of haemorrhages among these groups. These changes were more severe in patients with MCTD as compared to RNP+SLE. Ordinal logistic regression showed more severe reduction in capillary density in patients with $R N P+S L E$ as compared to RNP negative SLE $(O R=9.5, p=0.007)$ independent of the presence of Raynaud's, ILD and disease duration.

Conclusions: Presence of anti-U1RNP antibody is associated with micro-vascular abnormalities in SLE as detected by NFVC. Patients with MCTD have more profound abnormalities as compared to RNP +SLE patients.

Disclosure of Interest: None declared

DOI: 10.1136/annrheumdis-2018-eular.7013

\section{AB0618 PREVALENCE OF HYPOVITAMINOSIS D IN ADULTS WITH SYSTEMIC LUPUS ERYTHEMATOSUS AND THE RELATIONSHIP WITH SLEDAI 2K IN PATIENTS TREATED IN TWO RHEUMATOLOGY SERVICES, BOGOTA 2017}

R.A. Guzman Moreno, L.G. Piñeros, J. Garcia, L.M. Pombo, A. Teheran, J. Bustillo, K.A. Guzman Moreno, V. Cadavid, M.C. Mejia. Inmuno Reumatologia and Internal Medicine, IDEARG. Fundación Universitaria Juan N Corpas, Bogota, Colombia

Background: Vitamin D is a steroid hormone with pleiotropic effects on physiological processes. Among others, immune system regulation and their analogues prevent symptom development of autoimmune diseases such as SLE. A previous research in a colombian clinic found a prevalence of hipovitaminosis D of $87 \%$ in healthy population, but hypovitaminosis $D$ is higher in SLE patients than healthy controls.

Objectives: To establish the prevalence of hypovitaminosis D in patients with SLE and relationship with SLEDAI - $2 \mathrm{~K}$.

Methods: A cross sectional study was carried out. 80 medical records with a diagnoses of SLE o CIE-10 M30-M36 were identified and we included patients $>18$ years of age who meet at least 4 of the 11 criteria to diagnoses of SLE for medical record. The analysis included means, DS and Kruskall Wallis with p-value $<0.05$. Results: The majority of patients are women (94\%), with an average age of 39.9 years, married $(41 \%)$, with secondary education $(56.7 \%)$ and different occupations. It was found that the patients with higher activity, had lower vitamin D levels. Additionally, if the patient had lupus nephritis, vitamin $D$ levels decreased even more.

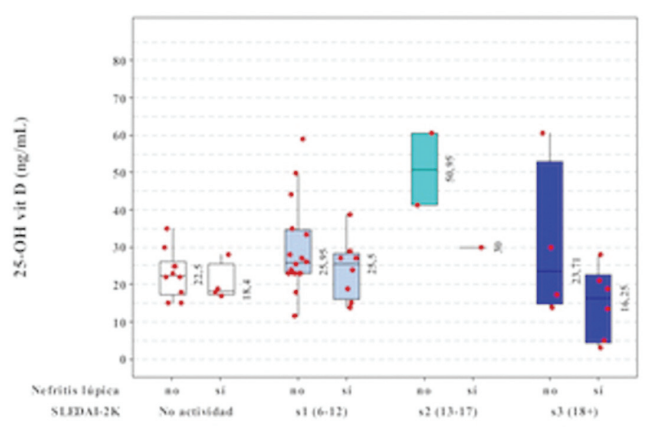

Abstract AB0618 - Figure 1

Conclusions: Patients with active systemic lupus Erythematosus, (SLE) have hypovitaminosis $\mathrm{D}$ more frequently and we noticed that patients with renal involvement have the lowest levels of vitamin D, which justifies a later analysis.

\section{REFERENCES:}

[1] American College of Rheumatology. Guidelines for referral and management of systemic lupus erythematosus in adults. Arthritis Rheum. 1999 Sep;42(9):1785-96.

[2] Simioni J, Heimovski F, Skare T. On lupus, vitamin D and leukopenia 2016;56(3):206-211.

[3] Guzman R.A, Piñeros L.G, Theran A, Flechas J, Mejía M. AB0795 Hypovitaminosis D and Calcium Intake of Adult Population in Bogota (DICAVITD). Ann Rheum Dis 2016;75:1175-1176.

[4] Alele J., et al. Autoimmun Rev 2010;9:137-39.

[5] Dall, era M., et al. in Kelley\&Firestein,s Textbook of Rheumatology. 10th Ed, Elsevier; Philadelphia 2017; 1368-89.

Disclosure of Interest: None declared

DOI: 10.1136/annrheumdis-2018-eular.3990

\section{AB0619 MANY PERIPHERAL FRACTURES DESPITE NORMAL BONE MINERAL DENSITYIN CAUCASIAN SLE PATIENTS}

R. Biesen, E. Wiebe, D. Freier, K. Zeiner, U. Schneider, T. Alexander, F. Hiepe, F. Buttgereit. Rheumatology, Charité, Berlin, Germany

Background: Clinical outcome has improved in systemic lupus erythematosus (SLE) and thus, early management of comorbidities like cardiovascular disease and osteoporosis has become highly important. In this disease, osteoporotic risk factors such as female gender, early onset of disease leading to long disease duration, high degree of systemic inflammation, high frequencies of glucocorticoid usage often at higher doses, and chronic fatigue or pain compromising physical activities are often present in combination. ${ }^{1}$ Rh-GIOP (NCT02719314) is an ongoing prospective study monitoring glucocorticoid (GC)-induced osteoporosis of rheumatic patients, established in $\mathbf{2 0 1 5}$ at the Charité University Hospital. To date, the database comprises clinical data and bone mineral density data meas ured by dual x-ray absorptiometry (DXA) of 592 patients with inflammatory rheumatic diseases

Objectives: To quantify bone mineral density and fractures in SLE patients.

Methods: Bone mineral density (BMD) data of SLE patients as measured by dual $\mathrm{x}$-ray absorptiometry (DXA) were analysed with regard to their relation to detailed clinical data.

Results: 43 female and 6 male SLE patients aged between 20 and 77 years (mean: 46.31 years) were assessed by DXA (all of Caucasian ethnicity, mean dis ease duration: 15.49 years; $61 \%$ denied any physical activity). SLE medication included glucocorticoids (93.9\%; mean cumulative dose: $25.5 \mathrm{~g}$ ), antimalarials $(67.3 \%)$, azathioprine (30.6\%), mycophenolate-mofetil acid $(22.4 \%)$, belimumab $(16.3 \%)$, cyclophosphamide $(10.2 \%)$ and methotrexate $(8.1 \%)$.

In $26(60,5 \%)$ of all studied SLE patients, $36(92.3 \%)$ peripheral and $3(7.7 \%)$ vertebral fractures were recorded. Notably, 6 of these patients with fractures were younger than 30 and only 4 older than 60 years. 10 of all 39 fractures $(25.6 \%)$ were low-trauma fractures. Of note, $11 / 26$ patients $(42.3 \%)$ with fractures had a normal BMD, 9/26 (34.6\%) osteopenia and 6/26 (23.7\%) osteoporosis, while only $4(15.4 \%)$ of them initially received anti-osteoporotic medication.

Conclusions: There is a high occurrence of peripheral fractures in SLE. Moreover, 4 out of 10 SLE patients developed fractures despite a normal BMD, stressing that this parameter is of limited value for correctly identifying the fracture risk in SLE. The analysis of a larger number of patients and in-depth analyses are necessary to improve management of osteoporosis and to better prevent fractures in SLE patients.

\section{REFERENCE:}

[1] "Bone Disease in Connective Tissue Disease/Systemic Lupus Erythematosus." Bultink IEM. Calcif Tissue Int. 2017 Sep 12

Disclosure of Interest: R. Biesen Grant/research support from: Amgen, BMS Celgene, Generic Assays GSK, Horizon, medac, Mundipharma, Pfizer and Roche, E. Wiebe Grant/research support from: Amgen, BMS, Celgene, Generic Assays GSK, Horizon, medac, Mundipharma, Pfizer and Roche, D. Freier Grant research support from: Amgen, BMS, Celgene, Generic Assays GSK, Horizon, medac, Mundipharma, Pfizer and Roche, K. Zeiner Grant/research support from: Amgen, BMS, Celgene, Generic Assays GSK, Horizon, medac, Mundipharma Pfizer and Roche, U. Schneider: None declared, T. Alexander: None declared, F. Hiepe: None declared, F. Buttgereit Grant/research support from: Amgen, BMS, Celgene, Generic Assays GSK, Horizon, medac, Mundipharma, Pfizer and Roche

DOI: 10.1136/annrheumdis-2018-eular.3429 